\title{
The Relationship Between Ambulatory Arterial Stiffness Index and Cardiovascular Outcomes in Women
}

\author{
Christopher J. Boos ${ }^{\text {a }, ~ b, ~ c, ~ d ~, ~ L i n ~ T h i r i-T o o n ~}{ }^{\text {a }}$, Christopher D. Steadman ${ }^{\text {a }}$, Sujata Khambekara, \\ Andrew Jordan ${ }^{\mathrm{a}}$, John Paul Carpenter ${ }^{\mathrm{a}}$
}

\begin{abstract}
Background: The ambulatory arterial stiffness index (AASI) obtained during ambulatory blood pressure monitoring (ABPM) has been cited as an independent predictor of major adverse cardiovascular events (MACEs) including cardiovascular death, stroke and worsening chronic kidney disease (CKD) among mixed-sex adult populations. This study aimed to determine the relationship between AASI and MACE and its predictive precision in women.
\end{abstract}

Methods: This work follows the guidelines of the STROBE initiative for cohort studies. This was a retrospective single-center observational study of adult women (aged 18 - 75 years), who underwent 24-h ABPM for the diagnosis of hypertension or its control. The primary endpoint was a composite MACE of cardiovascular death, acute limb ischemia, stroke, acute coronary syndrome (ACS), or progression to stage V CKD.

Results: A total of 219 women aged $57.4 \pm 13.3$ years were followed up for a median (interquartile range (IQR)) of 25.5 (18.3 - 31.3) months. Overall, $16(7.3 \%)$ patients suffered one or more MACE events. AASI was significantly higher in patients with known coronary artery disease (CAD), diabetes mellitus, peripheral vascular disease (PVD), heart failure, previous stroke, or transient ischemic attack (TIA). AASI was a significant predictor of MACE (area under the curve: 0.78; P $<0.001$ ) with an optimal cut-off of $\geq 0.56$. On Kaplan-Meier analysis AASI $\geq$ 0.56 was significantly associated with MACE (log-rank test, $\mathrm{P}<0.001)$. The only independent predictors of MACE on Cox proportional hazard analysis were diabetes mellitus, low high-density lipoprotein (HDL) levels, cumulative AASI values, or AASI $\geq 0.56$.

Conclusions: An AASI of $\geq 0.56$ is an independent predictor of

Manuscript submitted October 26, 2020, accepted November 12, 2020

Published online May 14, 2021

${ }^{a}$ Department of Cardiology, Poole Hospital NHS Foundation Trust, Longfleet Rd., Poole, Dorset, BH15 2JB, UK

bDepartment of Postgraduate Medical Education, Bournemouth University, Bournemouth, BH1 3LT, UK

${ }^{\mathrm{c} R e s e a r c h}$ Institute for Sport, Physical Activity and Leisure, Leeds Beckett University, Leeds, LS16 5LF, UK

${ }^{\mathrm{d}}$ Corresponding Author: Christopher J. Boos, Department of Cardiology, Poole Hospital NHS Foundation Trust, Longfleet Rd., Poole, Dorset, BH15 2JB, UK. Email: christopherboos@hotmail.com

doi: https://doi.org/10.14740/cr1189
MACE in women. A further validation study in a larger cohort of women is recommended.

Keywords: Ambulatory arterial stiffness index; Major adverse cardiovascular events; Women

\section{Introduction}

Current guidelines for the management of hypertension recommend the use of 24-h ambulatory blood pressure monitoring (ABPM) for the diagnosis of genuine hypertension and its differentiation into white-coat reactors [1-3]. Among the variety of derived variables obtained on ABPM the ambulatory arterial stiffness index (AASI) has emerged as an increasingly useful, yet indirect measure, of arterial stiffness. The AASI has been shown to correlate strongly with pulse wave velocity and pulse pressure, and has the advantage over several measures of arterial stiffness by its low cost and fully automated acquisition $[4,5]$.

AASI has been associated with target organ damage and major adverse cardiovascular events (MACEs) including stroke, myocardial infarction, acute limb ischemia, cardiovascular death, and worsening kidney function [6-9]. One of its additional advantages over other ABPM measures, as a potential cardiovascular disease (CVD) marker, is its lower vulnerability to short-term temporal changes in heart rate and blood pressure [10-12].

The data linking AASI to adverse cardiovascular outcomes mainly relate to adults with known hypertension. Despite its promise, the AASI has remained largely a research tool in practice despite this data being made available in several ABPM platforms. Despite accounting for approximately $50 \%$ of adults with hypertension, women have often been unrepresented in several studies [6, 13-15]. Moreover, it has been reported that women have higher AASI values than men of similar age [5]. Hence, a further understanding of the links between AASI and cardiovascular outcomes in women needs to be explored in greater depth.

This study had two principal aims. The first was to examine the relationship between AASI and adverse cardiovascular events in adult women. The second aim was to determine whether an optimal cut-off value for AASI could be determined to improve its potential for mainstream clinical use. 


\section{Materials and Methods}

\section{Population and design}

The STROBE Initiative Guidelines for cohort studies were followed [16]. This was a single-center retrospective observational study of consecutive adult women (aged 18 - 75 years), who underwent 24-h ambulatory blood pressure for the diagnosis or hypertension or assessment of its control from the March 1, 2017 to May 10, 2019. All tests were performed at Poole Hospital NHS Foundation Trust.

Patients with previous organ transplantation, persistent/ permanent atrial fibrillation, stage IV or $\mathrm{V}$ chronic kidney disease (CKD), active cancer, pregnancy, severe aortic stenosis, or aortic coarctation were excluded. Patients undergoing ABPM for the investigation of syncope with active infection or vasculitis or who had been hospitalised within the previous week were also excluded.

\section{The primary endpoint}

This was the occurrence of composite MACEs of cardiovascular death, stage V CKD, and nonfatal acute limb ischemia, stroke, or acute coronary syndrome (ACS) [7, 9]. ACS was defined in accordance with the European Society of Cardiology (ESC) guidelines and required the opinion of a cardiologist. The diagnoses of stroke and transient ischemic attack (TIA) were based on clinical presentation, supported by radiological imaging and had to be confirmed by a stroke physician. Acute limb ischemia was defined as a sudden decrease in limb perfusion causing a potential threat to limb viability and requiring hospitalisation. Coronary artery disease (CAD) was defined as a previous myocardial infarction, percutaneous coronary angioplasty/stenting, or a significant stenosis of $\geq 70 \%$ in $\geq 1$ major coronary arteries [17].

The occurrence of any MACE was censored using the hospital electronic patient records, which were available for Poole and the neighbouring Royal Bournemouth and Christchurch Hospitals. Only definite or highly probable diagnoses were used in the ascertainment of MACE.

\section{4-h ambulatory blood pressure measurement}

This was performed on a normal weekday by means of an automatic ABPM (Spacelab 90207, Spacelab Healthcare, Hertford, UK) using an automated oscillometric cuff that was placed on the nondominant arm. The device was set to measure blood pressure and heart rate at $30 \mathrm{~min}$ intervals throughout a $24-\mathrm{h}$ recording period. The night-time period was defined as the hours of 10:01 pm to 6:00 am, and the day-time period 6:01 am to 10:00 pm. Patients were only included if they had a minimum of 10 day-time and five night-time ambulatory blood pressure measures during the 24-h recording period [18].

The AASI was calculated, as 1 minus the regression slope of the diastolic to systolic blood pressure over the 24-h record- ing period [19]. The AASI ranges from a value of 0 to 1 with higher readings suggestive of stiffer arteries. The morning surge index was defined as $100 \times(1$ - (night average/morning average)). For this calculation the "morning" average = mean of all systolic values within the first $2 \mathrm{~h}$ after waking and the night average as the average of all values that within \pm 30 min of the minimum time $[20,21]$. The reported inter-observer paired differences in $24 \mathrm{~h}$ AASI recordings ( 2 - 5 weeks apart; $\mathrm{n}=423$ ) have been reported to be negligible (mean difference $\leq 0.01$ ) with repeatability coefficients of $50-60 \%$ suggesting modest repeatability $[22,23]$.

\section{Blood tests}

Venous blood for the measurement of lipid profile, full blood count, renal function, and glycated hemoglobin (HbAlc) were analyzed in our hospital laboratory and within 3 months of the ABPM measurements. The estimated glomerular filtration rate (eGFR) was calculated according to the Modification of Diet in Renal Disease (MDRD) Study equation based on patient age, sex, and ethnicity [24].

\section{Ascertainment of clinical events}

All patients were followed up for a minimum of 12 months or until death.

\section{Ethical approval}

This study and its experimental protocol were approved by the Poole Hospital Clinical Research and Innovation Department and the West of Scotland Research Ethics Committee (REC reference: 20/WS/0097); and the study was conducted in compliance with the ethical standards of the responsible institution on human subjects as well as with the Helsinki Declaration.

\section{Statistical analysis}

Statistical analyses were performed with SPSS 26.0 (SPSS, Chicago, IL, USA) and GraphPad Prism version 6.07 for Windows (GraphPad Software, San Diego, CA, USA). Data inspection and the D'Agostino-Pearson normality test were used to assess normality of all continuous data. Continuous data were presented as mean \pm standard deviation, except for highly skewed data where median and interquartile ranges were reported. Two group comparisons of continuous data were compared using an unpaired $t$-test or the Mann-Whitney $\mathrm{U}$ test for parametric and nonparametric data respectively. Categorical data were examined using Fisher's exact tests and Chi-square tests as appropriate. Correlations were investigated using Pearson and Spearman rank coefficients $( \pm 95 \%$ confidence interval (CI)) for parametric and nonparametric data, respectively. Only notable correlations with a coefficient $r \geq 0.20$ were reported.

A receiver operating characteristic (ROC) curve analy- 
sis was used to determine the optimal cut-off value of AASI to predict MACE. Kaplan-Meier analysis with log-rank test was conducted to compare the MACE-free survival using this AASI cut-off. Multivariate Cox regression analysis used to estimate the adjusted hazard ratio (HR) and 95\% CI for the univariate predictors $(\mathrm{P}<0.10)$ of the primary endpoint and determine the independent MACE predictors. Where there were multiple endpoints during follow-up, the time to the first event was considered for analysis of MACE. A P value of $<0.05$ was considered statistically significant.

\section{Sample size calculations}

Estimation of our sample size for sufficient power was performed using a proprietary sample size calculator (GraphPad StatMate version 2.00 for Windows). This was based on previous studies investigating the relationship of the AASI and cardiovascular events (cardiovascular death and nonfatal myocardial infarction and stroke) $[6,8,9,19]$.

We calculated that a sample size of at least 160 patients would have $\geq 80 \%$ power to detect a difference between AASI means (MACE vs. non-MACE group) of 0.15 at a significance level (alpha) of 0.05 (two-tailed).

\section{Results}

A total of 219 women were included. Their average age was $57.4 \pm 13.3$ years and the median duration of follow-up was 25.5 (18.3 - 31.3) months (Table 1). A total of 149 (68.0\%) patients had known previous CVD (CAD, previous stroke/TIA, peripheral vascular disease (PVD), hypertension, or heart failure).

Overall, $16(7.3 \%)$ patients suffered one or more MACE events. This included two cardiovascular deaths, four stroke/ TIAs, five ACSs, four episodes of acute limb ischemia, and one case of CKD stage $\mathrm{V}$. The univariate predictors of the primary endpoint were a history of diabetes mellitus, PVD, older age, decreased eGFR and high-density lipoprotein (HDL) cholesterol levels, use of statins or $\alpha$-blockers (Table 1). Among the 24-h ABPM variables, in AASI, the 24-h, day-time and night-time pulse pressures, and night-time systolic blood pressure were also greater among the patients who had suffered a MACE event (Table 2).

AASI was significantly higher in patients with known CAD $(0.53 \pm 0.02$ vs. $0.43 \pm 0.01 ; \mathrm{P}=0.004)$, diabetes mellitus $(0.50 \pm 0.03$ vs. $0.44 \pm 0.01 ; \mathrm{P}=0.03)$, PVD $(0.61 \pm 0.19$ vs. $0.45 \pm 0.16 ; \mathrm{P}=0.045)$, heart failure $(0.56 \pm 0.13$ vs. 0.45 $\pm 0.16 ; \mathrm{P}=0.03)$, stroke or TIA $(0.53 \pm 0.14$ vs. $0.44 \pm 0.17$; $\mathrm{P}=0.03)$ and with a previous history of CVD $(0.46 \pm 0.17$ vs. $0.41 \pm 0.16 ; \mathrm{P}=0.03)$.

AASI significantly correlated with age $(\mathrm{r}=0.49 ; 95 \% \mathrm{CI}$ : 0.39 to $0.59 ; \mathrm{P}<0.0001), \mathrm{HbA} 1 \mathrm{c}(\mathrm{r}=0.30 ; 0.15$ to $0.43 ; \mathrm{P}<$ $0.0001), 24-\mathrm{h}$ average systolic blood pressure $(\mathrm{r}=0.34 ; 0.22$ to $0.46 ; \mathrm{P}<0.0001$ ), pulse pressure ( $\mathrm{r}=0.56 ; 0.45$ to 0.64 ; $\mathrm{P}<0.0001)$, day-time systolic blood pressure $(\mathrm{r}=0.29 ; 0.16$ to $0.41 ; \mathrm{P}<0.0001)$, and pulse pressure $(\mathrm{r}=0.56 ; 0.46$ to $0.65 ; \mathrm{P}<0.0001)$, night-time systolic blood pressure $(\mathrm{r}=0.45$;
0.33 to $0.55 ; \mathrm{P}<0.0001)$, mean arterial pressure $(\mathrm{r}=0.31$; 0.18 to $0.42 ; \mathrm{P}<0.0001)$ and pulse pressure $(\mathrm{r}=0.50 ; 0.39$ to $0.60 ; \mathrm{P}<0.0001)$. AASI inversely correlated with $24-\mathrm{h}$ heart rate $(\mathrm{r}=-0.25 ;-0.37$ to $-0.11 ; \mathrm{P}=0.0002)$, systolic $(\mathrm{r}=-0.41$; -0.51 to $-0.29 ; \mathrm{P}<0.0001)$, diastolic $(\mathrm{r}=-0.54 ; 0.63$ to $-0.43 ; \mathrm{P}$ $<0.0001)$ and mean arterial pressure $(\mathrm{r}=-0.48 ;-0.58$ to -0.37 ; $\mathrm{P}<0.0001)$ dipping, day-time diastolic blood pressure $(\mathrm{r}=$ $-0.25 ;-0.37$ to $-0.12 ; \mathrm{P}<0.0001)$, estimated as well as eGFR $(-0.23 ;-035$ to $-0.1 ; \mathrm{P}=0.0008)$.

\section{Receiver operator characteristic for AASI to predict MACE}

On ROC analysis AASI significantly differentiated the patients with MACE (area under the curve: 0.78; $\mathrm{P}<0.001$ ). The optimal cut-off value for predicting MACE was an AASI of $\geq$ 0.56 (Fig. 1). The patients $(n=62)$ with an AASI $\geq 0.56$ were significantly older $(+9.2 \pm 1.9$ years; $\mathrm{P}<0.0001)$ with a lower eGFR (mean difference $-4.7 \pm 2.3 \mathrm{~mL} / \mathrm{min} / 1.73 \mathrm{~m}^{2} ; \mathrm{P}=0.04$ ) compared with patients with lower AASI values $(<0.56)$.

\section{Kaplan-Meier analysis}

Kaplan-Meier analysis was performed to compare the MACEfree survival rates of patients with an AASI $\geq 0.56 \mathrm{vs}$. $<0.56$. Patients with an AASI $\geq 0.56$ had a higher incidence of MACE (log-rank test, $\mathrm{P}<0.001$ ) (Fig. 2).

\section{Independent predictors of MACE}

Cox multivariate proportional hazard model was constructed to determine the independent predictors of MACE. This model included the univariate predictors of MACE along with the borderline predictors $(\mathrm{P} \leq 0.1)$ (Table 3$)$. The independent predictors of MACE were diabetes mellitus, lower HDL levels, and an AASI of $\geq 0.56$ (Table 3 ). AASI as a continuous variable in the same model (instead of an AASI $\geq 0.56$ ) was also a significant independent predictor (HR: $1.07 ; 1.02-1.1 ; \mathrm{P}=$ $0.008)$. None of the other 24 -h blood pressure variables used instead of AASI (to prevent collinearity) were significantly associated with MACE on multivariate analysis.

\section{Discussion}

This was the first study to investigate the relationship between AASI and MACE events in an unselected population of adult women. We found that both increasing AASI values and an AASI of $\geq 0.56$ were independent predictors of MACE.

The AASI is reported to be an indirect measure of arterial stiffness. AASI has been shown to be significantly correlated with pulse wave velocity, central pulse and blood pressure as well as both central and peripheral arterial augmentation index $[5,25]$. There is accumulating evidence supporting an association between the AASI and adverse cardiovascular events in- 
Table 1. Baseline Demographics and Clinical Characteristics of the Total Cohort and Patients With and Without MACE

\begin{tabular}{|c|c|c|c|c|}
\hline Characteristic & Full cohort & No MACE & MACE & P value \\
\hline Number & 219 & 203 & 16 & \\
\hline Age & $57.4 \pm 13.3$ & $57.0 \pm 13.50$ & $63.50 \pm 10.4$ & 0.047 \\
\hline Body mass, $\mathrm{kg}$ & $76.6 \pm 17.9$ & $81.80 \pm 22.23$ & $81.0 \pm 22.8$ & 0.32 \\
\hline Body mass index, $\mathrm{kg} / \mathrm{m}^{2}$ & $29.2 \pm 6.7$ & $29.1 \pm 6.6$ & $31.1 \pm 7.6$ & 0.26 \\
\hline Caucasian & $213(97.3 \%)$ & $197(97.0 \%)$ & $15(100 \%)$ & 0.99 \\
\hline Ischemic heart disease & $24(4.4 \%)$ & $21(10.3 \%)$ & $3(18.8 \%)$ & 0.39 \\
\hline Diabetes mellitus & $27(12.3 \%)$ & $20(9.8 \%)$ & $8(50.0 \%)$ & 0.0002 \\
\hline Previous stroke or TIA & $11(5.0 \%)$ & $9(4.4 \%)$ & $2(12.5 \%)$ & 0.19 \\
\hline Heart failure & $7(3.2 \%)$ & $5(2.5 \%)$ & $2(12.5 \%)$ & 0.09 \\
\hline Peripheral vascular disease & $4(1.8 \%)$ & $1(0.5 \%)$ & $3(20 \%)$ & 0.001 \\
\hline Hypertension & $146(66.7 \%)$ & $132(65.0 \%)$ & $14(87.5 \%)$ & 0.10 \\
\hline \multicolumn{5}{|l|}{ Smoking status } \\
\hline Current/ex & $85(40.7 \%)$ & $85(41.9 \%)$ & $4(25 \%)$ & 0.49 \\
\hline Never & $130(59.3 \%)$ & $118(58.1 \%$ & $12(75 \%)$ & \\
\hline \multicolumn{5}{|l|}{ Medication } \\
\hline ACE-I/ARB & $102(46.6 \%)$ & $92(45.3 \%)$ & $10(62.5 \%)$ & 0.20 \\
\hline Calcium channel blocker & $80(36.5 \%)$ & $72(35.5 \%)$ & $8(50.0 \%)$ & 0.28 \\
\hline Beta blockers & $51(23.3 \%)$ & $45(22.2 \%)$ & $6(37.5 \%)$ & 0.22 \\
\hline Diuretics & $36(16.4 \%)$ & $32(15.8 \%)$ & $4(25.0 \%)$ & 0.31 \\
\hline Alpha blockers & $20(9.1 \%)$ & $16(7.9 \%)$ & $4(25.0 \%)$ & 0.045 \\
\hline Statins & $63(28.8 \%)$ & $54(26.6 \%)$ & $9(56.3 \%)$ & 0.02 \\
\hline Aldosterone antagonists & $8(3.7 \%)$ & $8(3.9 \%)$ & $0(0 \%)$ & 0.99 \\
\hline Ejection fraction, $\%$ & $60.4 \pm 9.32$ & $60.4 \pm 9.5$ & $60.8 \pm 7.3$ & 0.88 \\
\hline Hemoglobin $\mathrm{g} / \mathrm{L}$ & $136.1 \pm 12.8$ & $136.3 \pm 12.9$ & $132.5 \pm 11.7$ & 0.26 \\
\hline Estimated glomerular filtration rate, $\mathrm{mL} / \mathrm{min} / 1.73 \mathrm{~m}^{2}$ & $70.8 \pm 15.5$ & $71.4 \pm 14.9$ & $63.0 \pm 20.4$ & 0.037 \\
\hline Total cholesterol, $\mathrm{mmol} / \mathrm{L}$ & $5.1 \pm 1.1$ & $5.1 \pm 1.1$ & $4.8 \pm 1.4$ & 0.34 \\
\hline HDL cholesterol, mmol/L & $1.7 \pm 0.5$ & $1.7 \pm 0.5$ & $1.3 \pm 0.3$ & 0.001 \\
\hline Triglycerides, $\mathrm{mmol} / \mathrm{L}$ & $1.5 \pm 0.9$ & $1.5 \pm 0.9$ & $1.7 \pm 0.9$ & 0.25 \\
\hline $\mathrm{HbA1c}$ & $42.0 \pm 14.0$ & $41.3 \pm 12.4$ & $49.9 \pm 26.1$ & 0.44 \\
\hline
\end{tabular}

MACE: major adverse cardiovascular event; TIA: transient ischemic attack; ACE-I: angiotensin-converting enzyme inhibitor; ARB: angiotensin II receptor blocker; HDL: high-density lipoprotein; HbA1c: glycated hemoglobin. $P$ values refer to the results of comparison between the MACE and non-MACE groups only.

cluding cardiovascular death, ACS, stroke and worsening renal function [7, 8, 19, 25]. Moreover, the AASI has been shown to independently predict cardiovascular mortality even among normotensive subjects [19]. Our results validate this previous research. One-third of our included patients were not known to have hypertension and the average day-time blood pressure at $135.8 \pm 16.7 \mathrm{~mm} \mathrm{Hg}$ was only just above the threshold for the diagnosis of hypertension. We observed a significant correlation between pulse pressure and AASI with higher AASI in patients with a higher burden of cardiovascular risk factors.

It has been previously reported that AASI also correlates with increasing age and 24-h mean arterial and systolic blood pressure [5]. Our data support this and further validate our findings. We also observed a significant association between
AASI and a wide range of atherosclerotic risk factors linked to the development of increased arterial stiffness, atherosclerosis, and CVD. We noted that AASI correlated with increased $\mathrm{HbA} 1 \mathrm{c}$ with significantly higher values in patients with diabetes mellitus, PVD, previous stroke/TIA, heart failure and $\mathrm{CAD}$, legitimising its role as a cardiovascular risk marker. Our observed correlation between AASI and decreased eGFR and lower eGFR among patients with an elevated AASI of $\geq 0.56$ again supports previous work. Mule et al also reported similar findings among a cohort of 143 untreated hypertensive subjects [26]. More recently, Erikson et al found AASI to be an independent risk factor for accelerated age-related temporal decline in GFR among a general middle-aged population [27].

In this study, both cumulative AASI values and an AASI $\geq$ 
Table 2. Baseline Demographics and 24-Hour Ambulatory Blood Pressure Readings of the Full Cohort and Those With and Without MACE

\begin{tabular}{|c|c|c|c|c|}
\hline Characteristic & Full cohort & No MACE & MACE & P value \\
\hline Number of readings & $29.5 \pm 3.7$ & $27.1 \pm 5.3$ & $26.8 \pm 5.3$ & 0.15 \\
\hline \multicolumn{5}{|l|}{ 24-h ABPM averages } \\
\hline Systolic blood pressure dip, $\mathrm{mm} \mathrm{Hg}$ & $9.6(4.2-14.1)$ & $9.6(4.8-14.1)$ & $7.5(0.44-15.1)$ & 0.16 \\
\hline Diastolic blood pressure dip, $\mathrm{mm} \mathrm{Hg}$ & $14.1(8.7-19.4)$ & $14.1(8.9-20.1)$ & $9.2(4.9-17.8)$ & 0.09 \\
\hline Mean arterial blood pressure dip, $\mathrm{mm} \mathrm{Hg}$ & $11.1(5.8-16.4)$ & $11.3(6.1-16.6)$ & $8.5(1.8-14.2)$ & 0.10 \\
\hline Systolic blood pressure, $\mathrm{mm} \mathrm{Hg}$ & $132.6 \pm 16.9$ & $132.3 \pm 16.9$ & $137.3 \pm 17.4$ & 0.12 \\
\hline Diastolic blood pressure, $\mathrm{mm} \mathrm{Hg}$ & $76.6 \pm 10.8$ & $76.9 \pm 10.9$ & $73.4 \pm 8.8$ & 0.15 \\
\hline Mean arterial pressure, $\mathrm{mm} \mathrm{Hg}$ & $96.3 \pm 11.2$ & $96.3 \pm 11.4$ & $96.4 \pm 9.2$ & 0.86 \\
\hline Pulse pressure, $\mathrm{mm} \mathrm{Hg}$ & $56.2 \pm 14.0$ & $55.5 \pm 13.5$ & $64.2 \pm 17.7$ & 0.02 \\
\hline \multicolumn{5}{|l|}{ Day-time averages } \\
\hline Systolic blood pressure, $\mathrm{mm} \mathrm{Hg}$ & $135.8 \pm 16.7$ & $135.5 \pm 16.7$ & $139.8 \pm 16.8$ & 0.16 \\
\hline Diastolic blood pressure, $\mathrm{mm} \mathrm{Hg}$ & $79.2 \pm 10.9$ & $79.6 \pm 11.1$ & $75.2 \pm 8.0$ & 0.13 \\
\hline Mean arterial pressure, $\mathrm{mm} \mathrm{Hg}$ & $99.0 \pm 11.2$ & $99.1 \pm 11.4$ & $998.3 \pm 8.3$ & 0.80 \\
\hline Pulse pressure, $\mathrm{mm} \mathrm{Hg}$ & $56.6 \pm 14.1$ & $56.0 \pm 13.6$ & $64.8 \pm 18.2$ & 0.02 \\
\hline \multicolumn{5}{|l|}{ Night-time averages } \\
\hline Systolic blood pressure, $\mathrm{mm} \mathrm{Hg}$ & $123.0 \pm 18.2$ & $122.2 \pm 17.8$ & $130.8 \pm 21.4$ & 0.07 \\
\hline Diastolic blood pressure, $\mathrm{mm} \mathrm{Hg}$ & $68.1 \pm 10.4$ & $68.2 \pm 10.3$ & $67.4 \pm 11.8$ & 0.79 \\
\hline Mean arterial pressure, $\mathrm{mm} \mathrm{Hg}$ & $87.7 \pm 11.8$ & $87.5 \pm 11.7$ & $90.7 \pm 12.9$ & 0.30 \\
\hline Pulse pressure, $\mathrm{mm} \mathrm{Hg}$ & $54.9 \pm 10.0$ & $54.2 \pm 13.5$ & $63.2 \pm 18.5$ & 0.02 \\
\hline Ambulatory arterial stiffness index & $0.45 \pm 0.16$ & $0.44 \pm 0.16$ & $0.60 \pm 0.15$ & $<0.0001$ \\
\hline Morning surge index & $0(0-9.7)$ & $0(0-10.2)$ & $0(0-7.8)$ & 0.86 \\
\hline
\end{tabular}

ABPM: ambulatory blood pressure monitoring; MACE: major adverse cardiovascular event; TIA: transient ischemic attack; ACE-I: angiotensin converting enzyme inhibitor; ARB: angiotensin II receptor blocker; HDL: high-density lipoprotein. P value refers to difference between MACE and nonMACE groups only.

0.56 were independent predictors of MACE. This defined cutoff may have useful practical value to transform the utility of the AASI from a research tool to one of genuine clinical use. Further validation of this cut-off in additional longitudinal studies would be helpful to better appreciate its translational impact. It is interesting that in a previous study of mixed-sex adults referred for ABPM for the diagnosis of hypertension, that the highest quintile of AASI was a value of $\geq 0.55$. The authors reported that subjects in this highest AASI group also had the greatest burden of cardiovascular risk factors (diabetes, older age, history of CVD, etc.). Unfortunately, the responsiveness of AASI to antihypertensive treatment has not been well demonstrated and appears to be marginal [28]. Consequently, its utility as a useful indicator of the efficacy of antihypertensive therapy and attenuation of cardiovascular risk has not been demonstrated to date.

In a previous meta-analysis, Aznaouridis et al examined the predictive value of the AASI for adverse cardiovascular events [29]. They included seven longitudinal studies over a mean follow-up of 7.8 years. They found that an increase in the AASI by one standard deviation was associated with an age, sex and risk factor relative risk increase in total cardiovascular events (cardiovascular deaths and nonfatal cardiovascular events) and stroke by $15 \%$ and $30 \%$, respectively. Interestingly, they observed that the AASI was a better predictor of cardiovascular events in women than men, emphasising the need to validate an AASI cut-off of 0.56 in men or in a mixed larger sex population. This is particularly relevant as it has been previously suggested that AASI values tend to be higher in women [5]. In a previous study comparing 189 women with 159 men of similar age (approximately 46 years), it was observed that sex was an independent determinant of AASI, and that AASI values were significantly higher in women than men $(0.38$ vs. 0.33$)$. Furthermore, they noted that the difference was far greater in in hypertensive subjects ( 0.45 vs. $0.31 ; \mathrm{P}=0.0001)$.

\section{Limitations}

This study has a number of limitations that should be acknowledged. This was a retrospective study. We used a broad definition of MACE. This selection of clinical events were specifically chosen prior to our data collection and were based on previously published data linking AASI to cardiovascular death, nonfatal stroke, ACS, limb ischemia and worsening renal disease. Endpoints were only adjudicated from our local hospital electronic records. Hence, we cannot not exclude the possibility 


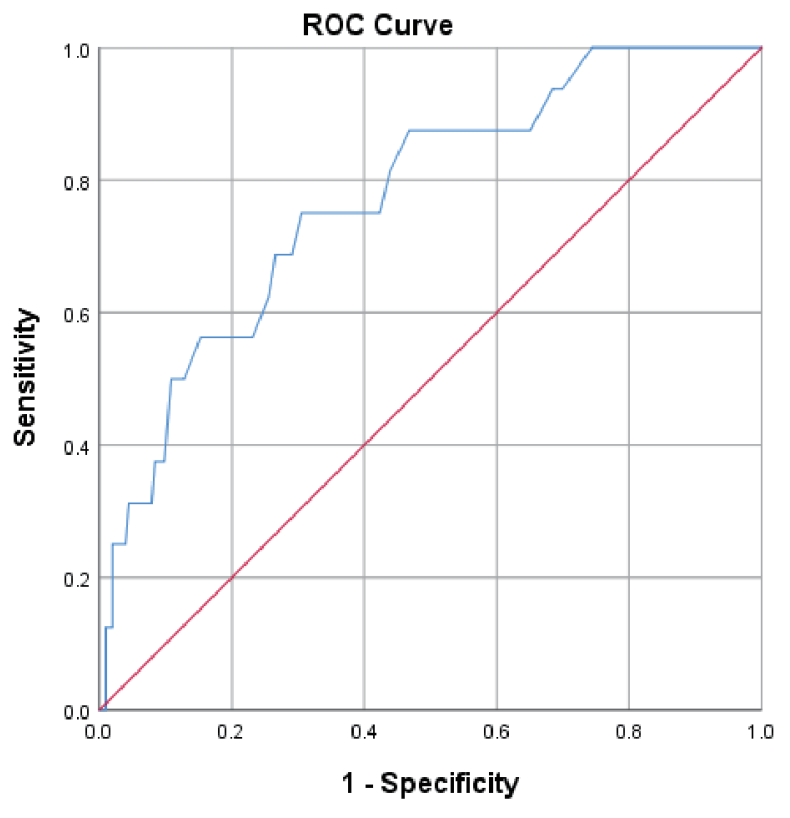

Diagonal segments are produced by ties.

Figure 1. Receiver operating characteristic curve of AASI for the prediction of major adverse cardiac events (MACEs).

there were undetected adverse cardiovascular events that were registered elsewhere. Our sample size was relatively small. Hence, we were not sufficiently powered to examine individual components of the primary endpoint. Nevertheless, this sample size was based on a robust power calculation and represents to our knowledge, the largest all-female study of AASI.

\section{Conclusions}

This was the first study to examine the relationship between
Table 3. Results of Cox Regression Analysis for Outcome of MACE

\begin{tabular}{lll}
\hline Variable & Hazard ratio $(95 \%$ CI) & P value \\
\hline Age & $1.05(0.98-1.12)$ & 0.18 \\
Diabetes mellitus & $5.4(1.3-23.4)$ & 0.02 \\
Peripheral vascular disease & $4.0(0.26-60.8)$ & 0.32 \\
AASI $\geq 0.56$ & $4.2(1.1-15.2)$ & 0.03 \\
eGFR & $1.02(0.98-1.06)$ & 0.28 \\
HDL cholesterol & $0.09(0.01-0.74)$ & 0.03 \\
Heart failure & $1.58(0.24-10.61)$ & 0.64 \\
Statin use & $1.76(0.54-5.7)$ & 0.35 \\
Alpha blockers & $0.26(0.02-2.7)$ & 0.26 \\
Hypertension & $1.90(0.37-0.7)$ & 0.44 \\
\hline
\end{tabular}

MACE: major adverse cardiovascular event; Cl: confidence interval; AASI: ambulatory arterial stiffness index; eGFR: estimated glomerular filtration rate; HDL: high-density lipoprotein.

AASI and cardiovascular events in an unselected group of adult women. We found that an AASI value of $\geq 0.56$ to be a significant and potentially useful clinical risk marker for the detection of patients at higher risk of adverse cardiovascular events.

\section{Acknowledgments}

We would like to thank the Research Department at Poole for their help with this research study.

\section{Financial Disclosure}

This study did not require any funding.

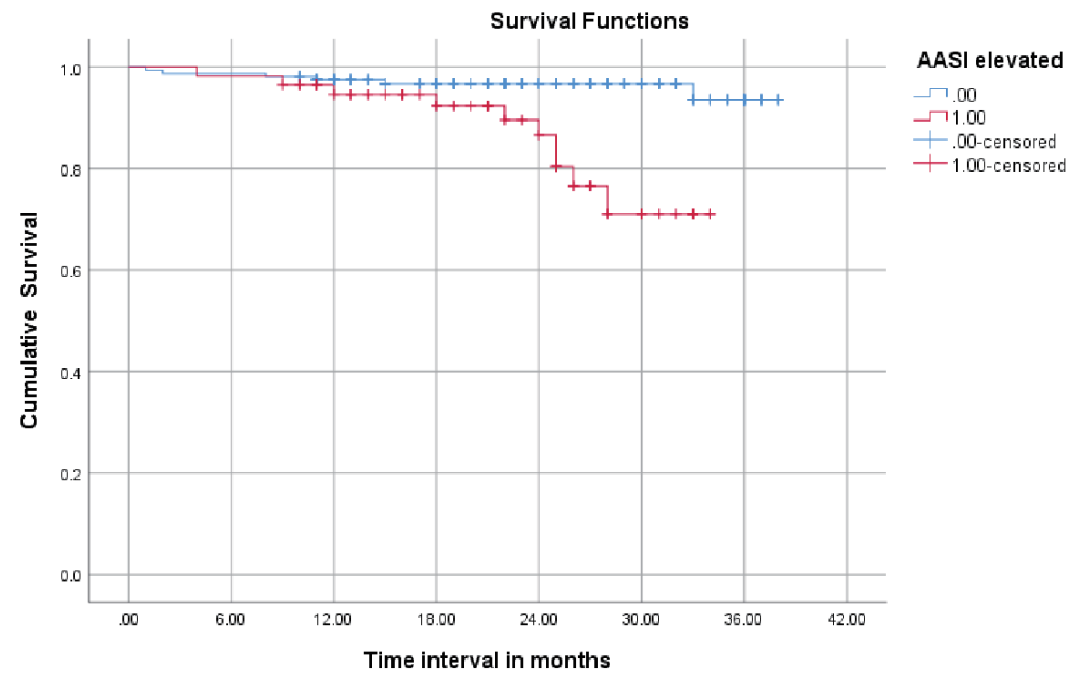

Figure 2. Kaplan-Meier survival analysis showing the event-free survival for major adverse cardiac events in patients with an AASI $\geq 0.56$ (red) versus $<0.56$ (blue line). AASI: ambulatory arterial stiffness index. 


\section{Conflict of Interest}

We have no conflict of interest to declare.

\section{Informed Consent}

As this was a registry study, the need for informed consent was deemed not to be necessary by the Ethics Committee.

\section{Author Contributions}

CJB designed the study, obtained ethical approval participated in event censoring, data collection and undertook the data analysis and wrote the first draft of the manuscript. LTT assisted with data collection, event censoring, data analysis and contributed to the editing of the manuscript. CDS, SK, AJ, and JPC assisted with study design, data collection and editing of the manuscript.

\section{Data Availability}

The authors would be willing to make their data available but only on a case by case basis and for a specific research use.

\section{References}

1. Williams B, Mancia G, Spiering W, Agabiti Rosei E, Azizi M, Burnier M, Clement DL, et al. 2018 ESC/ESH Guidelines for the management of arterial hypertension: The Task Force for the management of arterial hypertension of the European Society of Cardiology and the European Society of Hypertension: The Task Force for the management of arterial hypertension of the European Society of Cardiology and the European Society of Hypertension. J Hypertens. 2018;36(10):1953-2041.

2. Whelton PK, Carey RM, Aronow WS, Casey DE, Jr., Collins KJ, Dennison Himmelfarb C, DePalma SM, et al. 2017 ACC/AHA/AAPA/ABC/ACPM/AGS/APhA/ASH/ASPC/ NMA/PCNA guideline for the prevention, detection, evaluation, and management of high blood pressure in adults: a report of the American College of Cardiology/American Heart Association Task Force on clinical practice guidelines. Hypertension. 2018;71(6):e13-e115.

3. Boffa RJ, Constanti M, Floyd CN, Wierzbicki AS, Guideline C. Hypertension in adults: summary of updated NICE guidance. BMJ. 2019;367:15310.

4. Liu W, Zhou J, Chen J, Meng M, Li X, Gao C, Zhou J, et al. Ambulatory arterial stiffness index and its role in assessing arterial stiffness in dialysis patients. J Hypertens. 2017;35(6):1297-1301.

5. Li Y, Wang JG, Dolan E, Gao PJ, Guo HF, Nawrot T, Stanton AV, et al. Ambulatory arterial stiffness index derived from 24-hour ambulatory blood pressure monitoring. Hypertension. 2006;47(3):359-364.

6. Xu TY, Li Y, Wang YQ, Li YX, Zhang Y, Zhu DL, Gao
PJ. Association of stroke with ambulatory arterial stiffness index (AASI) in hypertensive patients. Clin Exp Hypertens. 2011;33(5):304-308.

7. Wang C, Zhang J, Li CC, Gong WY, Liu X, Ye ZC, Peng $\mathrm{H}$, et al. The ambulatory arterial stiffness index and target-organ damage in Chinese patients with chronic kidney disease. BMC Nephrol. 2013;14:257.

8. Kikuya M, Staessen JA, Ohkubo T, Thijs L, Metoki H, Asayama K, Obara T, et al. Ambulatory arterial stiffness index and 24-hour ambulatory pulse pressure as predictors of mortality in Ohasama, Japan. Stroke. 2007;38(4):11611166.

9. Muxfeldt ES, Cardoso CR, Dias VB, Nascimento AC, Salles GF. Prognostic impact of the ambulatory arterial stiffness index in resistant hypertension. J Hypertens. 2010;28(7):1547-1553.

10. Jin Y, Thijs L, Richart T, Li Y, Dolan E, Wang JG, Protogerou A, et al. Responses of the ambulatory arterial stiffness index and other measures of arterial function to antihypertensive drugs. Hypertens Res. 2011;34(4):489-495.

11. Liu Z, Hesse C, Curry TB, Pike TL, Issa A, Bernal M, Charkoudian N, et al. Ambulatory arterial stiffness index is not correlated with the pressor response to laboratory stressors in normotensive humans. J Hypertens. 2009;27(4):763768.

12. Leoncini G, Ratto E, Viazzi F, Vaccaro V, Parodi A, Falqui $\mathrm{V}$, Conti $\mathrm{N}$, et al. Increased ambulatory arterial stiffness index is associated with target organ damage in primary hypertension. Hypertension. 2006;48(3):397-403.

13. Gomez-Marcos MA, Recio-Rodriguez JI, Patino-Alonso MC, Gomez-Sanchez L, Agudo-Conde C, GomezSanchez M, Rodriguez-Sanchez E, et al. Ambulatory arterial stiffness indices and target organ damage in hypertension. BMC Cardiovasc Disord. 2012;12:1.

14. Zeng X, Jia N, Liu D, Wang L, Xu Z, Zhang Y, Wang H, et al. A cross-sectional study of the ambulatory central artery stiffness index in patients with hypertension. Medicine (Baltimore). 2019;98(26):e16053.

15. Ramirez LA, Sullivan JC. Sex differences in hypertension: where we have been and where we are going. Am J Hypertens. 2018;31(12):1247-1254.

16. von Elm E, Altman DG, Egger M, Pocock SJ, Gotzsche PC, Vandenbroucke JP, Initiative S. The Strengthening the Reporting of Observational Studies in Epidemiology (STROBE) Statement: guidelines for reporting observational studies. Int J Surg. 2014;12(12):1495-1499.

17. Neglia D, Rovai D, Caselli C, Pietila M, Teresinska A, Aguade-Bruix S, Pizzi MN, et al. Detection of significant coronary artery disease by noninvasive anatomical and functional imaging. Circ Cardiovasc Imaging. 2015;8(3).

18. Verdecchia P, Angeli F, Mazzotta G, Garofoli M, Ramundo E, Gentile G, Ambrosio G, et al. Day-night dip and early-morning surge in blood pressure in hypertension: prognostic implications. Hypertension. 2012;60(1):34-42.

19. Dolan E, Thijs L, Li Y, Atkins N, McCormack P, McClory $\mathrm{S}, \mathrm{O}^{\prime}$ Brien E, et al. Ambulatory arterial stiffness index as a predictor of cardiovascular mortality in the Dublin Outcome Study. Hypertension. 2006;47(3):365-370.

20. Stergiou GS, Mastorantonakis SE, Roussias LG. Morning 
blood pressure surge: the reliability of different definitions. Hypertens Res. 2008;31(8):1589-1594.

21. Kario K, Pickering TG, Umeda Y, Hoshide S, Hoshide Y, Morinari M, Murata M, et al. Morning surge in blood pressure as a predictor of silent and clinical cerebrovascular disease in elderly hypertensives: a prospective study. Circulation. 2003;107(10):1401-1406.

22. Dechering DG, van der Steen MS, Adiyaman A, Thijs L, Deinum J, Li Y, Dolan E, et al. Reproducibility of the ambulatory arterial stiffness index in hypertensive patients. J Hypertens. 2008;26(10):1993-2000.

23. Stergiou GS, Kollias A, Rarra VC, Roussias LG. Ambulatory arterial stiffness index: reproducibility of different definitions. Am J Hypertens. 2010;23(2):129-134.

24. Levey AS, Coresh J, Greene T, Stevens LA, Zhang YL, Hendriksen S, Kusek JW, et al. Using standardized serum creatinine values in the modification of diet in renal disease study equation for estimating glomerular filtration rate. Ann Intern Med. 2006;145(4):247-254.

25. Bastos JM, Bertoquini S, Polonia J. Prognostic significance of ambulatory arterial stiffness index in hypertensives followed for 8.2 years: its relation with new events and cardiovascular risk estimation. Rev Port Cardiol. 2010;29(9):1287-1303.

26. Mule G, Cottone S, Cusimano P, Incalcaterra F, Giandalia M, Costanzo M, Nardi E, et al. Inverse relationship between ambulatory arterial stiffness index and glomerular filtration rate in arterial hypertension. Am J Hypertens. 2008;21(1):35-40.

27. Eriksen BO, Stefansson VTN, Jenssen TG, Mathisen UD, Schei J, Solbu MD, Wilsgaard T, et al. High ambulatory arterial stiffness index is an independent risk factor for rapid age-related glomerular filtration rate decline in the general middle-aged population. Hypertension. 2017;69(4):651-659.

28. Kollias A, Rarra V, Karpettas N, Roussias L, O'Brien E, Stergiou GS. Treatment-induced changes in ambulatory arterial stiffness index: one-year prospective study and meta-analysis of evidence. Hypertens Res. 2015; 38(9):627-631

29. Aznaouridis K, Vlachopoulos C, Protogerou A, Stefanadis C. Ambulatory systolic-diastolic pressure regression index as a predictor of clinical events: a meta-analysis of longitudinal studies. Stroke. 2012;43(3):733-739. 